\title{
Bottom sediments affect Sonneratia mangrove forests in the prograding
}

\section{Mekong delta, Vietnam}

\author{
William Nardin ${ }^{1, *}$, Curtis E. Woodcock ${ }^{1}$ and Sergio Fagherazzi ${ }^{1}$ \\ ${ }^{1}$ Department of Earth and Environment, Boston University, Boston, MA, USA
}

*Author to whom correspondence should be addressed; E-Mail: wnardin@bu.edu;

\begin{abstract}
Mangrove forests exert a strong influence on tropical deltas by trapping sediments discharged by rivers and by stabilizing the substrate with roots. Understanding the dynamics of sediments and morphology in and around mangrove forests is critical in order to assess the resilience of coastlines in a period of accelerated sea level rise. In this research, sediment samples, mangrove forest characteristics, and remote sensing data are used to investigate the relationship between mangroves and sediment substrate in the Mekong Delta, Vietnam. Our data show a significant correlation between percent of sand in bottom sediments and density of Sonneratia caseolaris forest. We ascribe this result to higher sediment disturbance in muddy areas that prevents seedling establishment. This correlation potentially allows the determination of substrate characteristics from vegetation attributes detected by remote sensing, despite the impenetrability of the forest canopy. The results presented herein suggest that a supply of sand from the river and hydrodynamic processes moving the sand ashore control the density of the Sonneratia mangrove forests at this location, promoting tidal flat colonization and canopy expansion.
\end{abstract}




\section{Introduction}

Mangroves are commonly defined as an association of trees and shrubs forming the dominant vegetation in tidal, saline wetlands, along tropical and subtropical coasts. The ecological, social, cultural, and economic values associated with mangroves have been demonstrated in many studies (e.g. Kuenzer et al., 2011). Mangroves are also among the most threatened and vulnerable ecosystems: the habitat area loss during the last two decades is estimated to be about $36 \%$ of the total global mangrove area (Aschbacher et al., 1995; Spalding et al., 2010). As a result, there is an urgent need for conservation and restoration of these delicate environments.

Mangroves interact with sediment deposits through a complex and diversified roots system that varies for different mangrove species. Aerial roots are a common adaptation of mangrove trees to their saline environment, allowing root respiration despite the anaerobic substrate. Because mangroves colonize the shorelines where large rivers discharge, excess input of sediment to mangroves can affect forest health. Field observations show that mangrove trees die when a large portion of their roots are buried under a thick sediment layer (Ellison, 1998), although there is also evidence that some mangrove species can adjust to higher elevations resulting from sediment deposition (Rogers et al., 2005). Other studies show that mangrove propagules are sensitive to burial. Therefore high sediment deposition increases seedling mortality of mangrove species (Thampanya et al., 2002; Duke and Jackes, 1987). As a result, mangrove species and vegetation dynamics are different along prograding shorelines with respect to areas with limited sediment deposition, because sedimentation patterns control elevation and therefore vegetation zonation (Thampanya et al, 2002; Duke and Jackes, 1987). 
Thampanya et al., (2002) indicate that mangroves from the genus Sonneratia are suited for colonizing areas at lower intertidal elevations in Southeast Asia, even in locations potentially subject to abrupt high sedimentation rates.

Retrieving information with regard to the extent and condition of mangrove ecosystems is essential to support the management of these sensitive areas. Typical mangrove habitats are temporarily inundated and sometimes located in inaccessible regions; consequently, traditional field-based survey methods are time-consuming and cost-intensive. Remote sensing provides a cost-effective means to undertake large-scale, long-term monitoring and mapping. Remote sensing has been proven to be highly valuable in monitoring and mapping highly threatened mangrove ecosystems (Blasco et al., 2001; Simard et al., 2008; Kuenzer et al., 2011). For example, remote sensing data, often integrated with GIS, has been used to: assess structural and physiognomic parameters in mangroves (Blasco et al., 2011), measure mangrove height and above-ground biomass using SRTM (Simard et al., 2008), establish the impact of shrimp aquaculture on mangrove using SPOT imagery (Tong et al., 2004), and monitor change in extent of mangrove forests (Thu and Populus, 2007).

In this study, the relationships between a mangrove fringe forest and bottom sediments are investigated in the Mekong Delta, Vietnam, by means of a detailed field survey and the Normalized Difference Vegetation Index (NDVI) derived from Landsat images. NDVI is used worldwide to monitor vegetation dynamics, assess both abundance and richness of target species, evaluate the response of vegetation to either land use or climate change, and assess damage after severe storms (e.g. Sims and Thoms, 2002).

\section{Materials and Methods}

\subsection{Study site}

The study area is a fringe mangrove forest located between the two branches of the Song Hau River, which is one of the main distributaries of the Mekong River Delta in Vietnam. 
The study area, approximately $170 \mathrm{~km}$ southwest of Ho Chi Minh City and centered on $9^{\circ} 30^{`} \mathrm{~N}, 106^{\circ} 16^{\prime} \mathrm{E}$, is located in the northeast part of the Soc Trang province, bordering the Tra Vinh province in the Mekong Delta region (Figure 1). The Mekong river delta is among the world's largest deltas, encompassing about $39,000 \mathrm{~km}^{2}$ and supporting tens of millions of people in southwestern Vietnam. The delta is divided in nine distributaries separated by shore-perpendicular delta plains (Tamura et al., 2010).

The sedimentary dynamics of the delta and its coastal evolution have been studied by several researchers (e.g., Nguyen et al., 2000; Ta et al., 2002, 2005; Tanabe et al., 2003; Tamura et al., 2010; Nardin et al., 2015). The Quaternary evolution of the deltaic plain has been driven by spatially variable depositional and erosional events, with some shorelines prograding and some eroding because of the complex tidal regime and wave action around the delta. These events produced a series of sandy ridges, separated by depressions where clay and organic matter accumulated.

The study area is located in an almost flat region, densely populated and intensively farmed: paddy fields, along with shrimp ponds, salt pans and mangroves are the most conspicuous land-use unit in the landscape (Tang et al., 2004). The climatic conditions are moist tropical: the rainy season begins in late May to early July and ends during October to November (Tamura et al., 2010). The fringe forest faces the Southeast Asia Sea and it is influenced by its moderate wave energy and semidiurnal tide with amplitude ranging from 2.2 to $3 \mathrm{~m}$ at the coast. In theory, the Mekong River Delta's broad ecological, geomorphological and hydrological conditions are extremely favorable for the development of dense mangrove forests, but human legacies of war, collection of firewood, clearing for agriculture, and, more recently, shrimp farming has heavily reduced the total mangrove area in the delta. In our study area, the mangrove forest is dominated by Sonneratia spp. (predominantly Sonneratia caseolaris), which are more resistant to salinity and flooding, and thus colonize 
low-lying mudflats and tidal flats at the forest fringe. At intermediate elevations, Sonneriata spp. are replaced by Avicennia spp. (predominantly Avicennia marina) with higher leaf cover, by dense Nypa fruticans and Aegiceras corniculatum (see also Phan and Hoang, 1993).

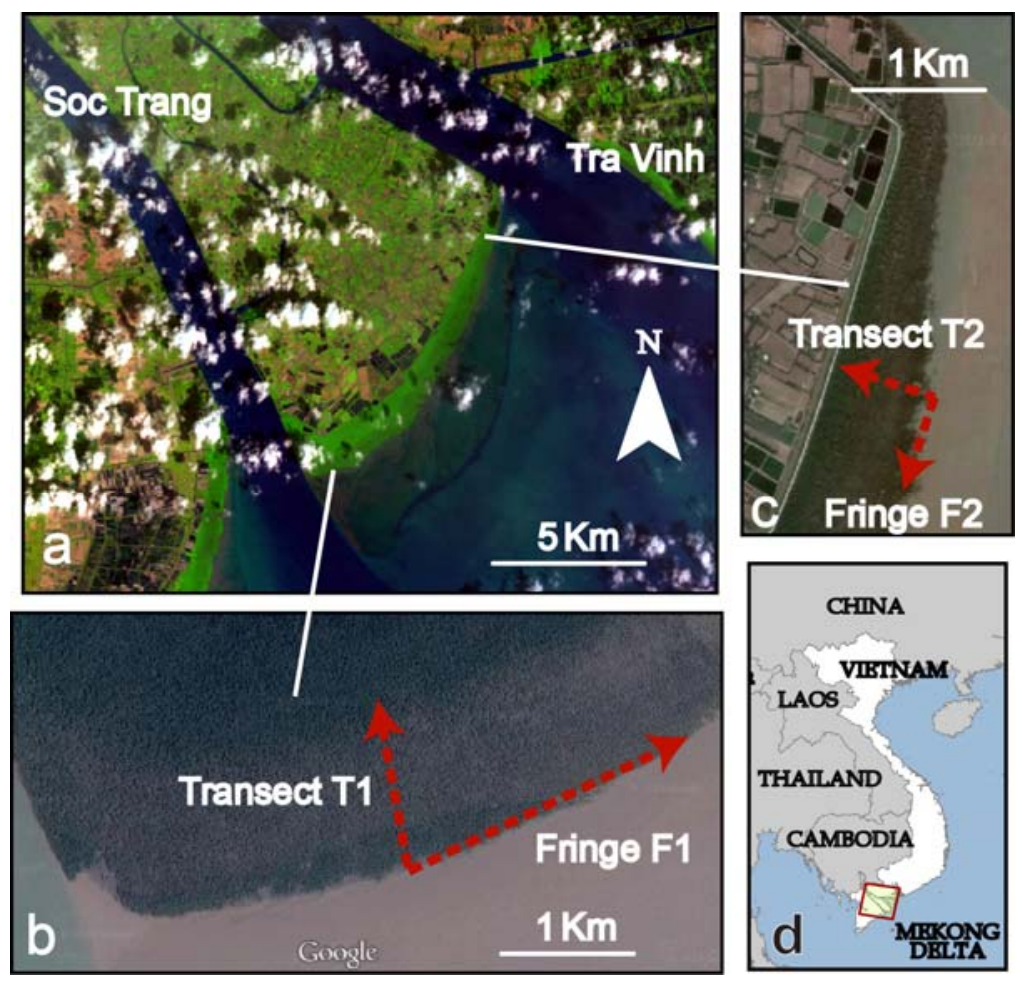

Figure 1. Study area in the Mekong river delta, a) Landsat 5 ETM image taken on February 11,2010 . The two aerial photographs b) and c) represent the study site with transects location (courtesy of Google Earth, Image 2006 GeoEye).

\subsection{Remote sensing data}

The vegetation index NDVI derived from Landsat data is defined as:

$$
N D V I=\frac{(N I R-R E D)}{(N I R+R E D)}
$$

where NIR and RED are the amounts of near infrared and red light, respectively, reflected by the vegetation and captured by the sensor of the satellite. The definition is based on the physical principle that chlorophyll absorbs in the red portion of the electromagnetic spectrum 
whereas the mesophyll leaf structure scatters the NIR portion (Kerr and Ostrovsky, 2003). NDVI is a normalized index that ranges from -1 (absence of vegetation) to +1 (presence of dense, healthy vegetation). The relationship between NDVI and vegetation productivity is well established, and the link between this index and the fraction of absorbed photosynthetic active radiation intercepted has been well documented both theoretically (Sellers et al., 1992) and empirically (Asrar et al., 1984). In our study we use a Landsat 7 image retrieved on 19 April 2014 (LE71250532014109EDC00). We extracted NDVI values for all the sampling points along transect T1. Along the fringe (transect F1 and F2), we did not analyze NDVI. In fact, the NDVI value is influenced by the possible presence of bare tidal flat in a Landsat pixel (the mangrove shoreline often dissects a Landsat pixel, so that part of it is mangroves and part of it is unvegetated tidal flat).

The Landsat surface reflectance products delivered by USGS are radiometrically calibrated across sensors and orthorectified to ground control points to facilitate comparison of multitemporal imagery. Atmospheric effects have been removed and observations converted to surface reflectance using the widely accepted LEDAPS (Landsat Ecosystem Disturbance Adaptive Processing System) algorithm (Masek et al., 2006). The brightening effect of clouds and the darkening effect of cloud shadows affect remote sensing analyses, leading to inaccurate atmospheric corrections, biased estimation of NDVI values, errors in land cover classification, and false detection of land cover change. Therefore, the image has also been screened for clouds and cloud shadows using the Fmask algorithm developed by Zhu \& Woodcock, (2012). 

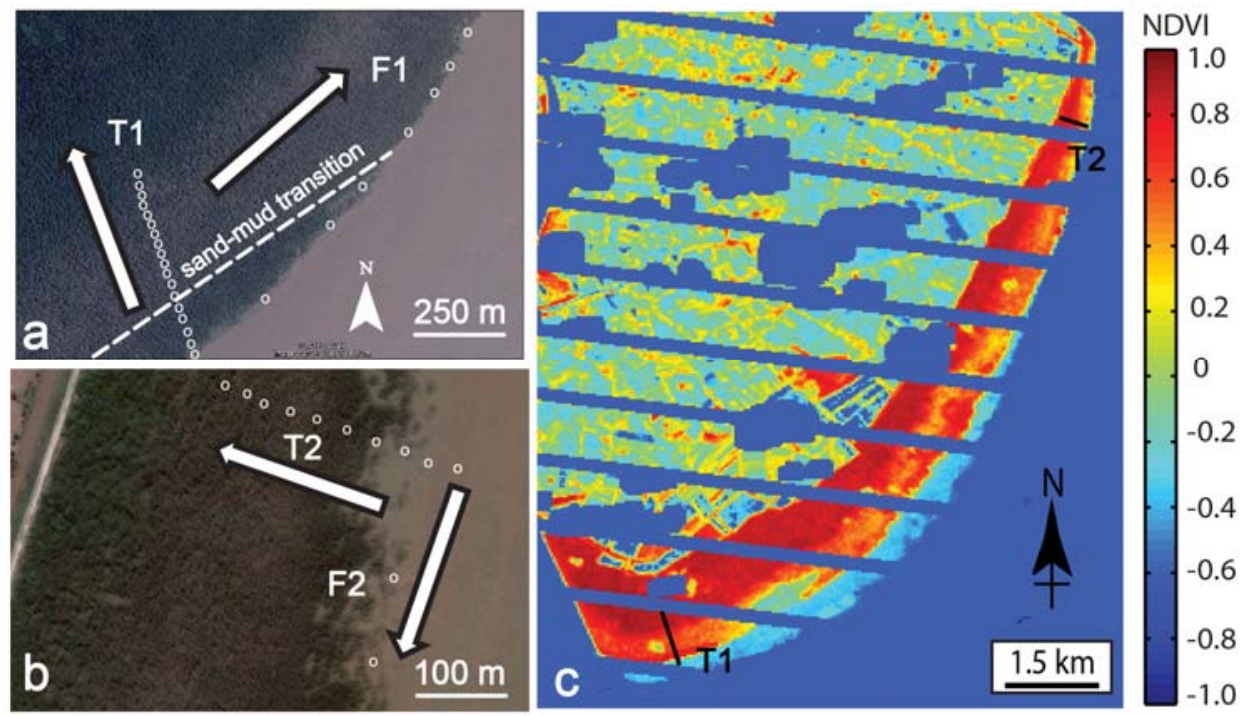

Figure 2. Locations where bottom samples and forest data were taken: a) along transects T1 and $F 1, b$ ) along transects $\mathrm{T} 2$ and F2. The dotted line indicates the sand -mud transition detected along the T1 transect (the sand is seaward while the mud is landward). White arrows show the numerical sequence of the samples. c) Normalized Difference Vegetation Index (NDVI) for the Mekong river delta, Vietnam (Landsat 7ETM image from 19 April 2014). Black lines indicate the location of the analyzed transects.

\subsection{Sediment characteristics}

Sediment samples were collected for grain size and soil density analyses along four transects in the fringe forest of $\mathrm{Cu}$ Lao Dung Island during low tide (white circles in Figure 1). Transects $\mathrm{T} 1$ and $\mathrm{T} 2$ are perpendicular to the shoreline while transects $\mathrm{F} 1$ and $\mathrm{F} 2$ run along the forest/water boundary (Figure 1 and 2). The data were collected every $30 \mathrm{~m}$ along $\mathrm{T} 1$ and $\mathrm{T} 2$ in order to match the Landsat resolution. The entire survey was carried out between 10 September and 5 October 2014, taking 15 days in total. The study took place during the Monsoon season, which was characterized by river discharge and low wave energy along the coast.

The locations of the samples, recorded with a handheld GPS, were chosen to cover areas in proximity of the two river mouths (Figure 1). Absolute elevations along transects T1 and T2 were measured using a Topcon Hiper Lite + Plus GPS GLONASS L1 L2 RTK and a Topcon 
GTS 252 Total Station. The RTK georeferenced the transect points outside of the mangrove canopy using the Vietnam 2000 datum and the WGS 84 ellipsoid, thus allowing the direct comparison between the elevations of the two transect that are located $10 \mathrm{~km}$ apart. Inside the canopy, where the RTK antenna was not receiving the satellites signal, we used the Total Station, relying on the points whose elevation was measured with the RTK as benchmarks. The Total Station had to be moved several times along transects given the density of the tropical canopy.

Two sediment samples were collected at each location. A fixed sediment volume of $10 \mathrm{~cm}^{3}$ was taken with a plastics syringe to a depth of $4-5 \mathrm{~cm}$ in order to determine sediment bulk density and percent of organic matter. The sample was weighed wet and then dried after desiccation to constant weight in a convection oven at $60^{\circ} \mathrm{C}$. To determine percentage organic matter, a loss on ignition technique was used with samples ignited at $400^{\circ} \mathrm{C}$ for 12 hours/days. Percentage organic matter was based on the proportion of sample lost following ignition. A second sample was taken to determine the grain size distribution; specifically to identify the percentage of sand, silt and clay size particles. This second sample was sonicated and wet-sieved to separate vegetation and mud from sand. After drying, each component (vegetation, mud, and sand) was weighed to determine weight percentage composition. The sand was then dry sieved in a Ro-Tap RX-29 to determine grain size distribution, using the standard five sieves $(62,125,250,500$ and $1000 \mathrm{~mm})$. The mean grain size and sorting for the sand fraction were determined using the geometric method of moments in GRADISTATv8 software (Blott and Pye, 2001).

Shear strength was measured in all the sampling locations with a Humbolt shear vane device. Shear strength measurements were collected in all cases near or at saturation (Leonard and Richard, 2004; Watts et al, 2003). 


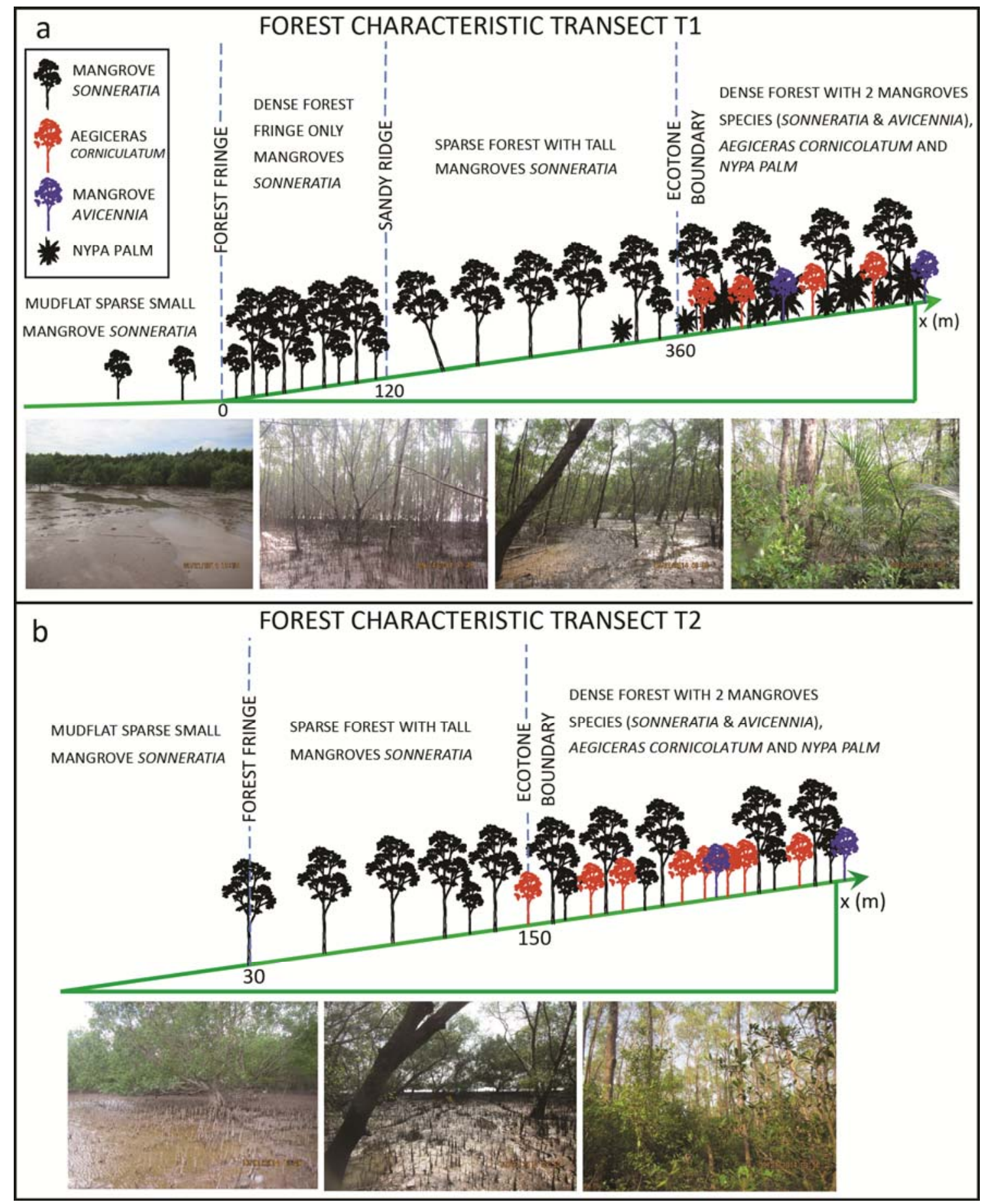

Figure 3. Vegetation sequence along a) transect $\mathrm{T} 1$ and $\mathrm{b}$ ) transect $\mathrm{T} 2$. Vertical dotted lines denote a forest or geological feature detected from remote sensing and field data. Different vegetation species identified on site are reported in the upper left corner of a). Trees dimensions are scaled following the dimensions measured in the field. Photographs show vegetation distribution in different zones of transects. 


\subsection{Vegetation survey}

To determine forest characteristics, we collected vegetation data along the four mangrove transects. We used the variable circular plot method (Grosenbaugh, 1952; Dilworth and Bell, 1975; Simard et al., 2008) to survey tree density. Using a Basal Area Factor (BAF) of 10, we tallied a total of 242 trees, an average of 8 trees per plot. Figure 3 shows a sketch of the natural vegetation variability found within the mangrove forest. We further divided the sampled trees in 3 size categories as a function of DBH (large, medium and small) and counted how many trees fell in each category within a radius of $10 \mathrm{~m}$ from the transect points. At each location we measured height and $\mathrm{DBH}$ of one tree representative of each category. A full survey of all trees in the plot was impossible due to the presence of very aggressive wasps that nested in large numbers on the Sonneratia trees.

To measure solar light penetrating the Sonneratia canopy, HOBO pendant temperature/light data loggers were installed on 7 Sonneratia caseolaris trees, 5 along transects $\mathrm{T} 1$ and 2 along $\mathrm{T} 2$, at the same height of $1.8 \mathrm{~m}$ from the soil. Sensors were consistently positioned with an eastern orientation. The HOBO sensors measured the solar light that can penetrate the forest canopy. Given the unique spectral sensitivity of the data loggers, the light sensor is most useful for determining relative changes in light intensity, rather than absolute values of intensity. Geographical location was acquired with a handheld GPS (Global Positioning System).To establish relationships between the vegetation variables (BAF and number of trees), the NDVI, and sediment characteristics, we used linear regressions utilizing the available samples in the Sonneratia zone only (29 sample points out of 38 total). 

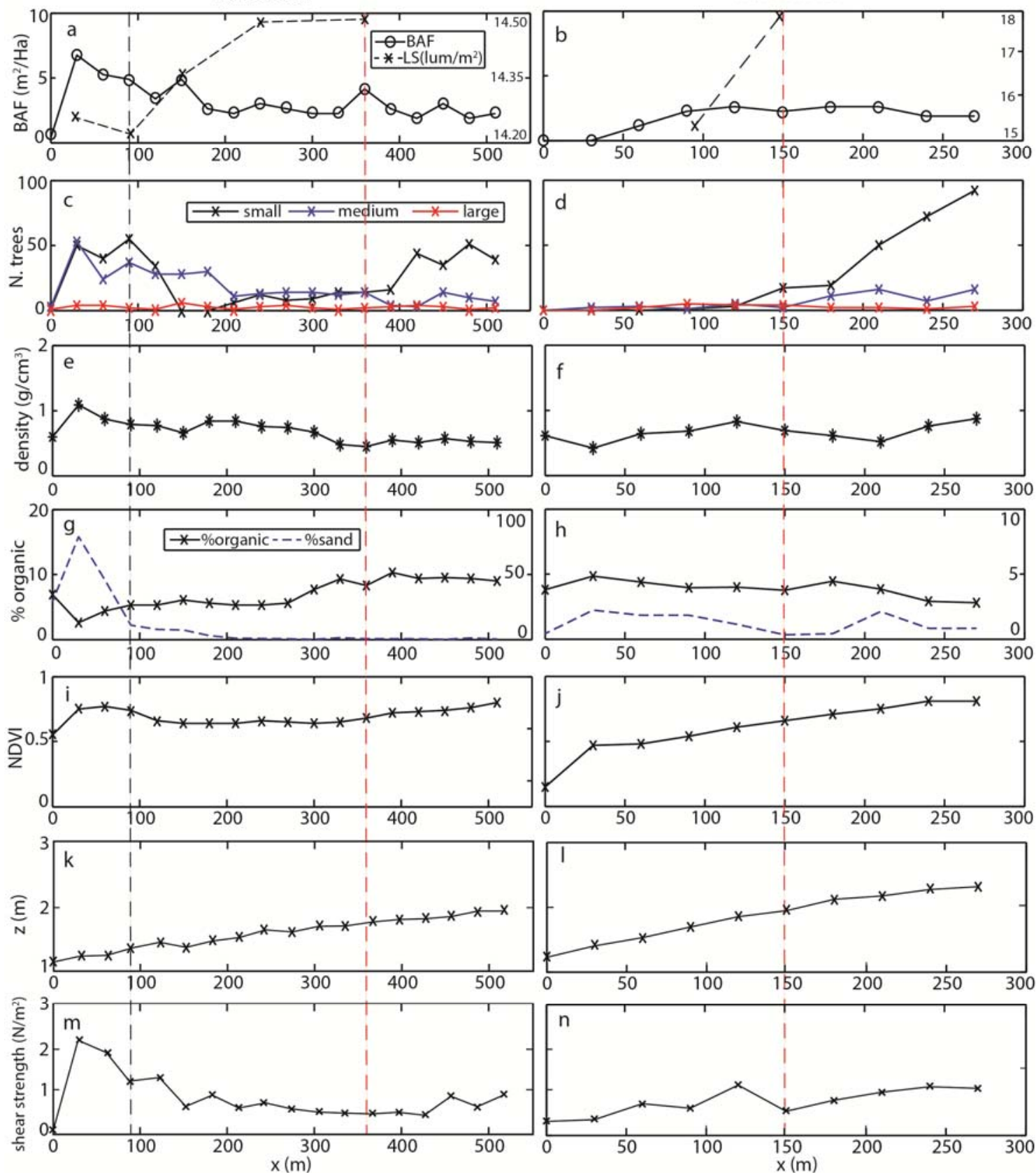

Figure 4.a,b) Basal Area Factor and light intensity absorbed by the HOBO sensor along transect $\mathrm{T} 1$ and T2; c,d) number of trees; e,f) sediment density; g,h) percentage of sand and organic matter; i,j) NDVI; $k$,l) transect elevation; $m, n$ ) soil shear strength. Data in the first column refers to transect $\mathrm{T} 1$ while data in the second column refers to transect $\mathrm{T} 2$. Crosses in the different plots represent the sampling point along each transect. Vertical black dashed lines shows the position on transect $\mathrm{T} 1$ of the sand-mud transition identified during the survey. Vertical red dashed lines represent the point at which new mangrove species are present. 
Fringe $\mathrm{F} 1$
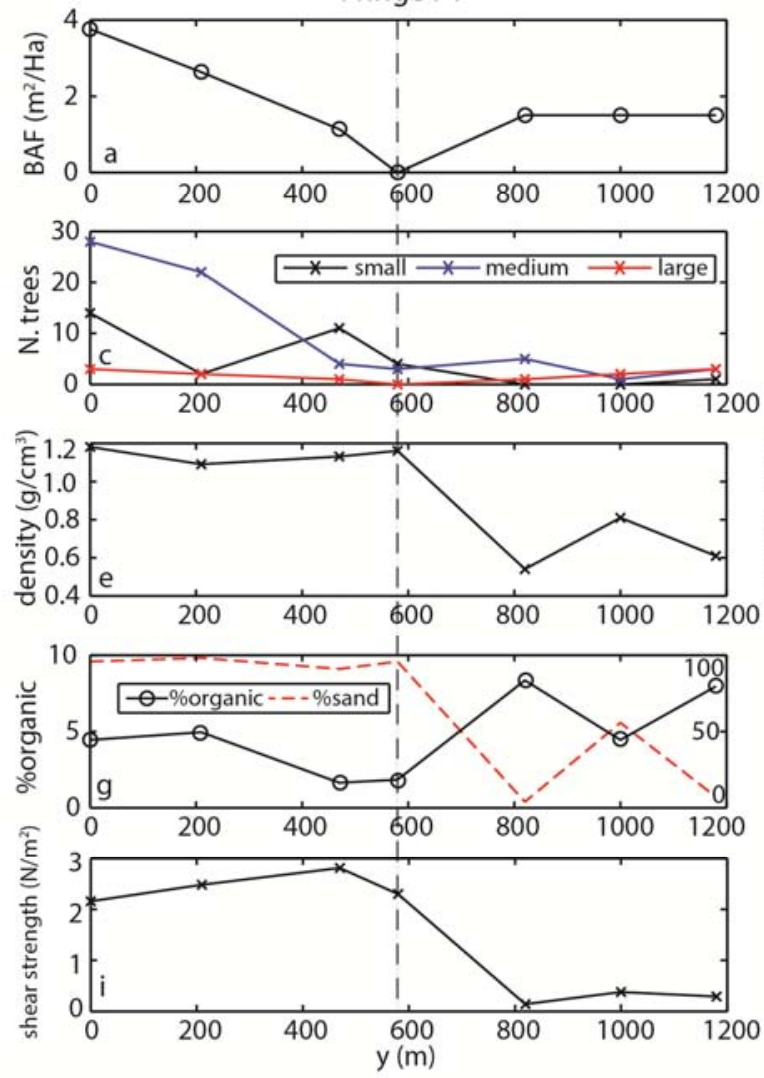

Fringe F2
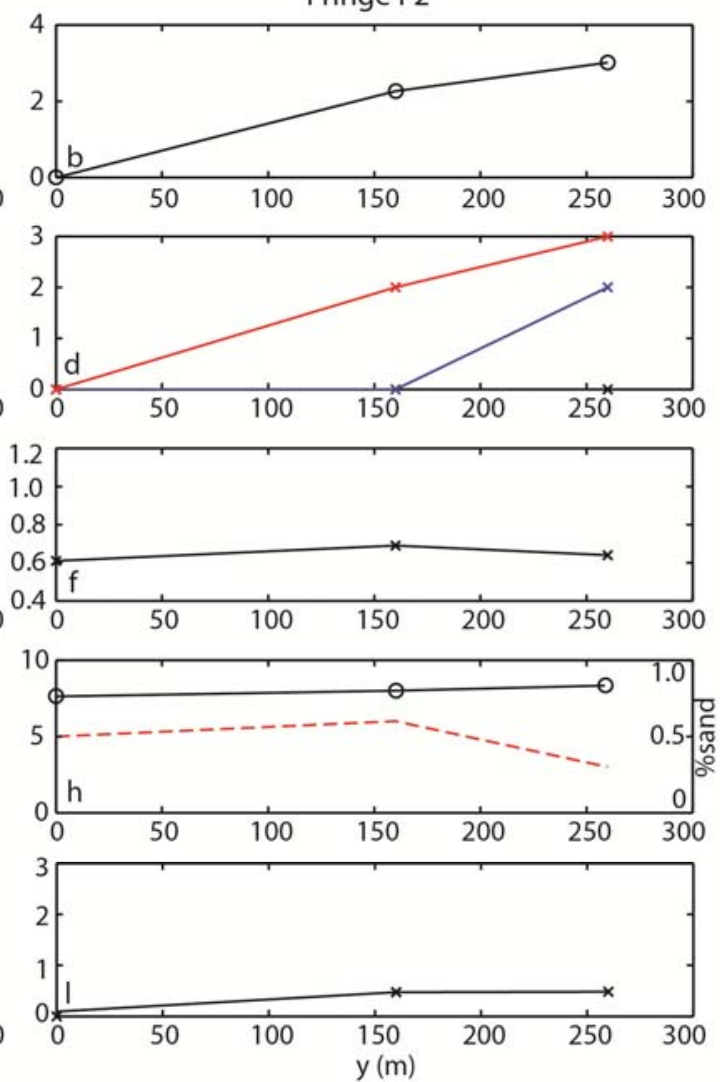

Figure 5. a,b) Basal Area Factor along transects F1 and F2; c,d) number of trees; e,f) sediment density; g,h) percentage of sand and organic matter; and i,l) soil shear strength. Data in the first column refer to transect F1 while data in the second column refer to transect F2. Marks in the different plots represent the sampling point along each transect. Vertical black dashed lines shows the position on transect F1 where the sand-mud transition line intersect the forest fringe. After that sample point the sediment characteristics switch from primarily sand to mud.

\section{Results}

\subsection{Sediment characteristics}

The distribution of sand in bottom sediments has different characteristics in the South West fringe (SW) where transects T1 and F1 are located (Figure 2a) with respect to the North East fringe (NE) where we established transects T2 and F2 (Figure 2b). Sediment density along transect T1 (Figure 4g) is higher at the seaward boundary of the mangrove forest and decreases linearly inside the forest, while on T2 sediment density slightly oscillates around the value of $0.8 \mathrm{~g} / \mathrm{cm}^{3}$. Fringe transect F1 (Figure 5e) shows an abrupt drop in sediment 
density after $800 \mathrm{~m}$. The SW sediment samples were characterized by a high sand fraction, with an average grain size of $140 \mu \mathrm{m}$. Our samples displayed a peak in concentration of sand (79.5\%) immediately inland of the mangrove shoreline. In the NE area sand is almost absent (when present, the average grain size is $160 \mu \mathrm{m}$ ) with values up to $2 \%$ (Figure $4 \mathrm{j}$ ).

We did not find a significant difference in sand sorting between the two areas (Welch's ttest with $p<0.05$ ). The mud fraction is higher in the SW after the sand-mud line (average of $98.8 \%$ ) while it is lower along the mangrove shoreline $(69.5 \%)$. On the fringe, approximately $800 \mathrm{~m}$ from transect $\mathrm{T} 1$, the sediment shows an abrupt transition from mostly sand to mostly mud (Figure 5e and 5g). Sediment characteristics do not change in the NE part of the island along transects T2 and F2 (average sand content of 1.3\%, Figure 5f,h).

The bottom shear strength is high in the sandy area at the beginning of $\mathrm{T} 1$, and then decreases landward in locations where more mud is present (Figure 4e). Generally, bottom shear strength is related to sediment density and percent of sand (Figure 4f, 5e,f).

Most sample locations at both transects have an elevation between $1 \mathrm{~m}$ and $2 \mathrm{~m}$ with respect to the datum (Figure $4 \mathrm{k}, 1)$. The two transects have a different slope: the slope of $\mathrm{T} 1$ is 0.0016 (Figure 4k) while the slope of T2 is 0.0051 (Figure 4l). New vegetation species (Aegiceras corniculatum and Nypa fruticans) appear approximately at the same elevation in the two transects $(1.88 \mathrm{~m}$ in $\mathrm{T} 1$ and $1.92 \mathrm{~m}$ in $\mathrm{T} 2)$, despite the fact that transects are located $10 \mathrm{~km}$ apart and have different slopes.

\subsection{Forest characteristics determined from field data}

The Sonneratia forest displays a high tree density with average height and diameter in the shoreline part of transect T1 (Figure 4a,c). After approximately $120 \mathrm{~m}$, mature and sparse Sonneratia trees are present until a distance of $360 \mathrm{~m}$ from the shore, where Sonneratia individuals co-exist with Avicennia marina, Aegiceras corniculatum and Nypa fructicans 
increasing vegetation density. Most of those species (Avicennia marina, Aegiceras corniculatum and Nypa fructicans) compete with mature and tall Sonneratia trees. This is because Sonneratia spp. establish at low positions in the tidal frame; over time, as elevation increases, the trees age and there is no addition of younger individuals as they are no longer in an ideal elevation for establishment.

In the shorter transect T2, at the forest fringe, Sonneratia trees are sparse with large diameters and, again, at a distance of $150 \mathrm{~m}$ inland the presence of young Avicennia trees and Aegiceras bushes increases vegetation density (Figure 4b,d). For Sonneratia trees, our sampling set has an average DBH of $2.0 \mathrm{~cm}$ and height of $2.0 \mathrm{~m}$ for small trees, a DBH of $16.8 \mathrm{~cm}$ and height of $16.2 \mathrm{~m}$ for medium mangroves, and a DBH of $31.6 \mathrm{~cm}$ and a height of $18.0 \mathrm{~m}$ for large trees. We find a discontinuity of mangrove density along the transect F1 away from the river mouth (SW site, Figure 5a,c), with decreasing number of small and medium size Sonneratia trees. Along transect F2 the forest did not show any significant variation (NE site, Figure 5b,d).

Light sensors installed along T1 show a minimum in luminosity corresponding to high vegetation density, while in the central part of the transect $\mathrm{T} 1$ tree density is lower and light intensity is higher (Figure 4a). Along transect T2, significant changes in luminosity are a function of different tree dimensions. In fact, large trees of medium height present at the fringe are replaced inland by tall trees with a reduced crown thus increasing light availability (Figure 4b).

\subsection{Estimation of mangrove forest density from NDVI}

Transect T1 displays a distribution of NDVI in space which is high at the beginning (shoreward) and at the end of transect (landward, Figure 4i). In the middle of the transect vegetation loses brightness and the NDVI decreases. The NDVI exhibits a sharp peak at the 
boundary between vegetation and ocean. In transect T2 (Figure 4j) the NDVI distribution is relatively constant along the transect. 

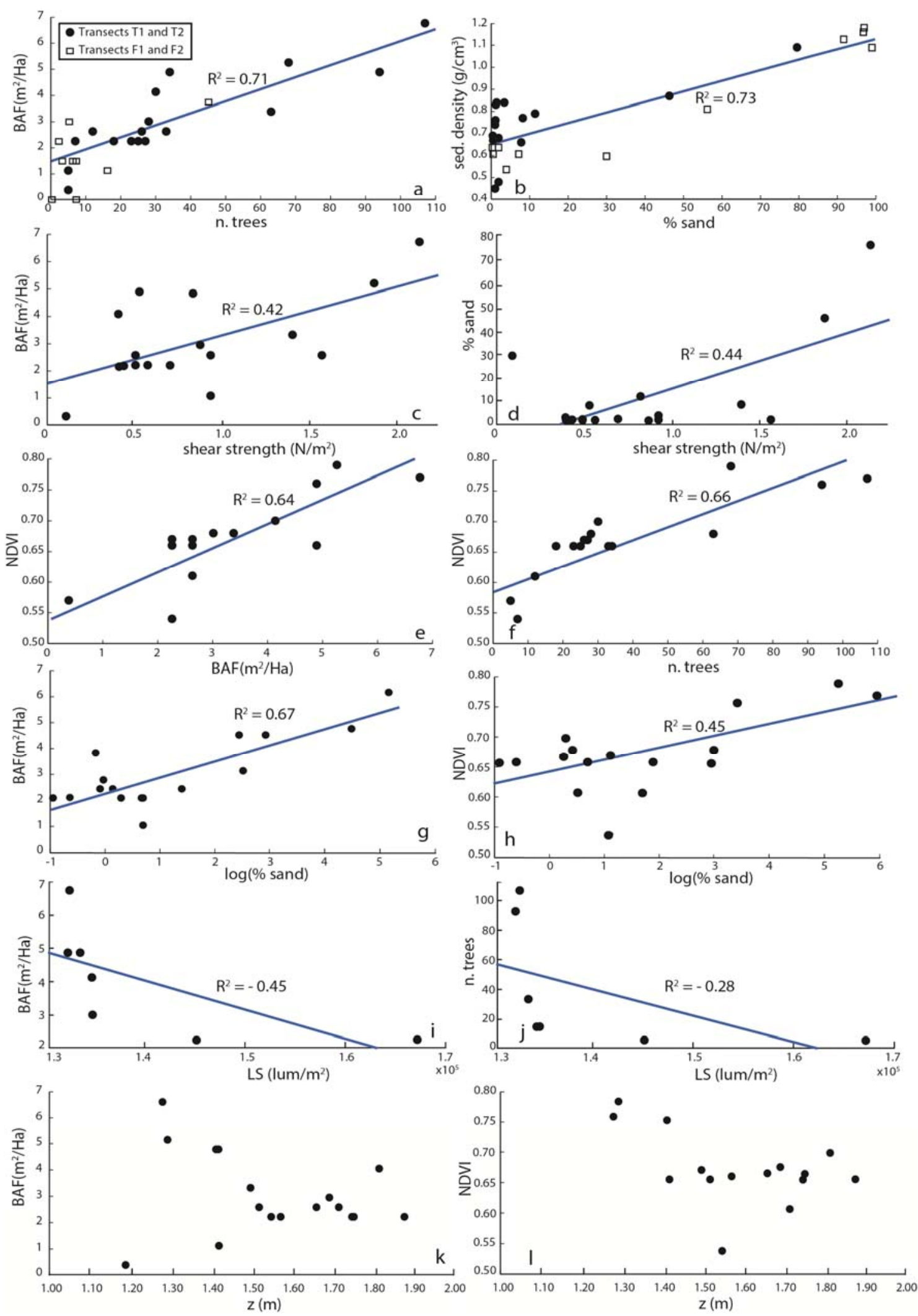

Figure 6. Relationships between the different variables measured along transects $\mathrm{T} 1, \mathrm{~T} 2$ and along the fringe boundary F1, F2. a) BAF as a function of number of trees. b) Density of 
bottom sediments as a function of percentage of sand. Bottom shear strength as a function of: c) Basal Area Factor (BAF) and d) sand percentage. NDVI as a function of e) BAF, f) number of trees. Percentage of sand at the bottom as a function of g) BAF and h) NDVI. Only NDVI data collected along T1 and T2 were used. Light Intensity absorbed by the HOBO sensor (LS) as a function of i) BAF and $\mathrm{j}$ ) number of trees. Elevation as function of $\mathrm{k}$ ) BAF and 1) NDVI.

\subsection{Relationships between forest density, sediment characteristics, elevation and}

\section{NDVI.}

Total number of trees per plot and BAF are correlated (Figure $6 \mathrm{a}, R^{2}=0.71, p<0.05$ ), so that both parameters can be used to define forest density. The sediment density in the analyzed samples increases with increasing fraction of sand (Figure 6b, $R^{2}=0.73, p<0.05$ ). Soil shear strength well correlates with vegetation density (Figure $6 \mathrm{c}, R^{2}=0.42, p<0.05$ ) and percentage of sand (Figure $6 \mathrm{~d}, R^{2}=0.44, p<0.05$ ). NDVI strongly correlates with both BAF

(Figure 6e, $R^{2}=0.64, p<0.05$ ) and number of trees (Figure 6f, $R^{2}=0.66, p<0.05$ ). We also find that BAF and NDVI are proportional to the percentage of sand along transects T1 and T2 (Figure $6 \mathrm{~g}, R^{2}=0.67, p<0.05$ and Figure $6 \mathrm{~h}, R^{2}=0.45, p<0.05$ ). In this analysis we have not include NDVI values along the fringe because they are affected by the bare area at the sea side, which reduces the overall NDVI value. Because high canopy density implies less light absorbed by the sensors, light intensity (LS) shows a significant inverse correlation with BAF (Figure 6i, $R^{2}=-0.45, p<0.05$ ) and number of trees (Figure $6 \mathrm{j}, R^{2}=-0.28, p<0.05$ ). Moreover, we find that BAF and NDVI are not correlated to the Sonneratia forest elevation (Figure 6k, $R^{2}=-0.06, p>0.05$ and Figure $61, R^{2}=-0.05, p>0.05$ ).

\section{Discussion}

The forest analyzed herein is a tropical mangroves environment in a tidal dominated delta with a large amount of sediment discharge (Thu and Populus, 2007; Wang et al., 2008). On transect $\mathrm{T} 1$, in the first $360 \mathrm{~m}$, only Sonneratia caseolaris is present but with significant 
differences in size and health status (Figure 4a,e and h). Dense Sonneratia forest is present at the sea boundary and becomes sparse moving inland. On the contrary, the forest boundary in Transect T2 is characterized by very sparse and mature Sonneratia trees. Duke and Jackes, (1987) show that Sonneratia seeds are intolerant to shade and consequently propagule establishment is more likely at the frontal water edge of the mangrove forest. This is the reason why we did not find Sonneratia saplings in the mature forest.

The two analyzed parts of the deltaic island essentially differ in terms of bottom sediments and vegetation characteristics. While both areas are close to the river mouths, the SW fringe has sandy substrates and high vegetation density, while the NE fringe has muddy bottom sets and a sparse canopy with mature trees (Figure 3). Our field data suggests that Sonneratia caseolaris thrives on sandy soil at this location and especially at the tidal flat-forest boundary. Several mechanisms could be responsible for the relationship between forest density and substrate characteristics. The most likely cause of high seedling density in sandy substrates is the reduced potential for sediment disturbance with respect to muddy environments. Balke et al., (2013) indicate that erosive events removing as little as $1-3 \mathrm{~cm}$ of bottom sediments lead to failure of young seedlings of Sonneratia alba. Soft mud can be removed more easily than sand, given its lower critical shear stress for erosion. Cycles of erosion and deposition can therefore prevent seedling establishment. This is particularly true for the fringe mangroves in the Mekong delta, which experiences sediment deposition during the summer season and wave erosion during the winter monsoons (Tamura et al., 2010). The active sediment layer that can be reworked every year is probably thicker in a muddy area with respect to a sandy area, since it is easier to remove recently deposited soft mud. In our field area sediments with a large sand fraction have high shear strength (Figure 6d). Bottom shear strength is a qualitative proxy for critical shear stress for erosion in tidal environments (Watts et al., 2003), particularly when the substrate is smooth as in tidal flats 
(Leonard and Richard, 2004). Therefore bottom sets with a large sand fraction are more difficult to erode by wave action and tidal currents. On these stable sediments, the Sonneratia forest seems thriving (Figure 6c).

It is important to point out that the observed reduction in forest density in muddy substrates might be valid only in this energetic environment. In areas where the energy of waves and currents is weaker, Sonneratia mangroves can flourish along muddy shorelines (Duke and Jakes 1987). This is because fine sediments are usually deposited in sheltered coastal areas, and are therefore subject to limited disturbance. Only near the mouth of major rivers, where the input of sediments is very high, we can find prograding muddy shorelines in high energetic conditions (Woodroffe, 2003). In these locations waves and tides constantly rework the soft mud deposits possibly disturbing propagule establishment.

Sandy sediments could also allow higher oxygenation of the roots because of their permeability, thus leading to a healthier mangrove forest. On the contrary, impermeable muddy substrates could potentially lead to reducing soil conditions and high concentration of sulfide. Mckee (1993) shows that soil rich in sulfide causes a decrease in both belowground and aboveground biomass of Avicennia germinans seedlings. High sulfide concentrations also affect growth of Red Mangroves (Rizophora mangle) (Lin and Sternberg, 1992). However, Gleason et al. (2003) indicate that Sonneratia alba can grow in soils with very low redox potentials, possibly suggesting high tolerance to sulfides.

Another possible mechanism is the higher stability of sandy substrates. In muddy areas we noticed significant scour near the trunk and pneumatophores of mangroves, probably due to an increase in turbulence during strong tidal flows. Localized scour led to mangrove tilting and some collapses at the beginning of transect T2. The softness of the substrate along transect T2 with respect to the sandy part of T1 (compare Figure 4e and Figure 4f) might prevent the establishment of a dense forest. 
An alternative explanation for the reduced tree density without invoking sediment characteristics would be root smothering due to sediment burial. Ellison, (1998) indicates that sediment burial impacts mangroves reducing plant vigor and possibly causing death. Ellison (1998) notes that the pneumatophores of Sonneratia could extend upward to counteract sedimentation, but this adaptation takes time, and is therefore effective only for low sedimentation rates. Finally, Ellison, (1998) reports several cases in Southeast Asia where sediment burial affected Sonneratia forest, concluding that these mangroves are intolerant of rapid accretion. Sediment burial would explain the reduced forest density in the landward part of transect T1, because the thickness of the deposited sediments is higher inland due to delta progradation (Fricke et al., 2016). However, burial would not explain the lower density of Sonneratia forest at the beginning of transect $\mathrm{T} 2$, which has the same low elevation of the beginning of transect $\mathrm{T} 1$ (compare Figure $4 \mathrm{k}$ to 41 ) and therefore limited thickness of deposited sediments.

Another hypothesis is that vegetation is responding to the creation of a sedimentary surface that is at the correct elevation within the tidal frame for Sonneratia to establish, independently of the presence of sand or mud. This would explain the high density of the forest at the beginning of transect T1, which is fast prograding (see Nardin et al., 2016), but it would not explain why the forest density is low in the landward part of T1, which formed by progradation as well, or the difference in vegetation characteristics we noticed at the transition between sand and mud along F1 (Figure 6a,c), despite the entire area is prograding. This hypothesis would not even explain why the forest density is lower along transect T2, since also this area was formed by progradation, even though not in recent years (see Nardin et al., 2015). Clearly more research is needed to fully understand why the Sonneratia forest is denser on sandy substrates in the Mekong Delta.

The Normalized Difference Vegetation Index (NDVI) derived from 30-meter resolution 
Landsat imagery was applied here to determine the spatial characteristics of the mangrove forest. NDVI data were then compared to BAF, number of trees, and light penetration under the canopy measured in the field. Our data highlights the important role of the frontal part of the mangrove forest on delta progradation. In fact in this area higher density of trees occurs on sandy substrates, resulting in a high density of roots and increased sedimentation. After analyzing 30 years of remote sensing images of the Mekong delta, Nardin et al., (2016) indicated that fast mangrove expansion is characterized by two geomorphic signatures: 1) a linear shape of the forest boundary with the ocean; 2) high values of NDVI at the mangrove's forest fringe. During our field survey those two features were studied in detail. In fact, the prograding transect $\mathrm{T} 1$ is characterized by a higher density of saplings (Figure 4c) while the receding fringe in transect $\mathrm{T} 2$ is dominated by large and medium trees. The mangrove saplings likely encroached on an elongated sandy deposit that was emplaced at the shore by storm events. The shape of the sand bar results in a linear forest boundary, while the high density of saplings is responsible for the high NDVI values. We further show that high NDVI values at the forest fringe are correlated to bottom sediment characteristics (Figure 7).

During the wet summer season, the Mekong River discharges large volumes of mud and sand through the river mouths. These sediments are deposited on the expansive tidal flats in front of the mangrove forest. During the winter monsoon, energetic storms rework the newly deposit sediment. Winds blowing from northeast create a long-shore current that moves sediment southwestward, sometimes forming sand ridges at the shore (Tamura et al., 2010). When a large sand deposit is placed at the shore, the mangrove forest finds optimal condition for expansion. In fact, high elevations and stable sandy soil allows fast vegetation encroachment by a dense canopy of saplings, with high biomass detected by high NDVI values. These sandy deposits are more frequent in the SW area, given the direction of the wind during the winter monsoon. Moving along the fringe transect F1, we found that the sand 
transported by waves accumulates up to a certain distance from the river mouth, after which the bottom becomes muddy with a distinct variation in forest characteristics.

Sediment distribution in the mangrove forests of the Mekong delta is affected by the interaction between vegetation, fluvial and tidal hydrodynamics. One of our results indicates that it might be possible to retrieve information about the nature of bottom sediments in a prograding delta from the characteristics of the mangrove canopy. In Figure $7 \mathrm{~d}$ we show a possible reconstruction of bottom sediments beneath the forest canopy based on NDVI data and the regression relationship reported in Figure 6e. Sandy sediments are only present at the SW forest boundary where high NDVI values were measured. Clearly this method requires a thorough validation with a much larger dataset. Identification of similar conditions elsewhere would attest to the efficacy of a broader relationship between vegetation density and sediment characteristics.

The correlation between mangrove vegetation and sediment pathways presented herein is likely valid only in areas where the shoreline is fast prograding because of the availability of large quantities of both sand and mud. A sorting mechanism, separating sand from mud during progradation is also necessary to give rise to different vegetation characteristics on the two substrates; this is however relatively common along shorelines, where waves and currents often sort sediments. Our results can thus be applied to tropical deltas and river mouths with large sediment loads where Sonneratia species are dominant.

Interestingly, the density of the Sonneratia forest is independent of substrate elevation even when other mangrove species are not present. The forest displays high BAF in the sandy area of $\mathrm{T} 1$ and low BAF in the muddy area of $\mathrm{T} 2$ despite the two areas are at the same elevation (Figure 6k). This is in contrast with the transition from Sonneratia forest to the Aegericas corniculatum and Nypa fruticans zone, which occurs at the same elevation for both transects 
(Figure $4 \mathrm{k}, \mathrm{l}$ ). Elevation thus seems controlling vegetation zonation, as seen in many other intertidal ecosystems (e.g. Silvestri et al., 2005), but not the density of the Sonneratia forest.

Thampanya et al., (2006) analyzed mangrove colonization rates in the southern part of Thailand with Landsat images. They measured different expansion rates as a function of coastal morphology (river mouths or sheltered bays) and mangrove density. At the river mouth, the presence of mangroves and a persistent input of riverine sediments are crucial to maintain coastal stability. Similarly, in our study we find a different behavior of the mangrove fringe depending on sediment availability.

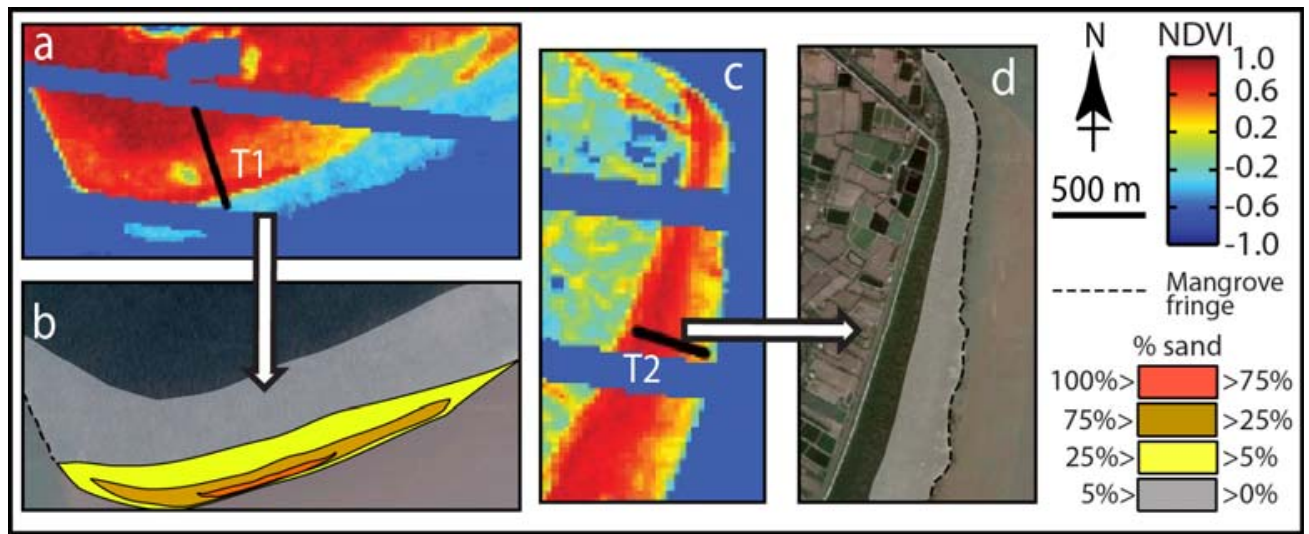

Figure 7.Landsat image of the mangrove fringe and relative sediment pattern computed from NDVI data. a,b) High NDVI values on the frontal part of the forest indicate high concentration of sand at the bottom. c,d) Low NDVI values on the mangrove's fringe with almost absence of sandy sediments.

\section{Conclusions}

Here we have studied how bottom sediments affect the mangrove species Sonneratia caseolaris in the Mekong River delta, Vietnam (Figure 7). Our results show that a sandy substrate plays a key role in the expansion of Sonneratia forest on tidal flats. In particular, we determine a direct correlation between forest density and percent of sand within the forest fringe. Our data presented here suggest that sand supplied by the river is important for the robustness of Sonneratia mangrove forests. 
We also show that NDVI values calculated from remote sensing images relate well to forest characteristics and, indirectly, correlate with the distribution of bottom sediments. The correlation between sediment characteristics and density of Sonneratia forest is probably unique of this study area, where the large sediment input from the Mekong River favors the deposition of both mud and sand at the shore. Energetic wave events during winter potentially disturb soft muddy substrates, preventing propagule establishment, while stable sandy bottemsets could favor mangrove encroachment. Our study seems indicating that the distribution of Sonneratia mangroves reflects an opportunistic response to geomorphic changes occurring in the landscape, which include sediment deposition and erosion. Sediment deposition is driven by sediment availability, while sediment erosion is mediated by sediment characteristics, tides and waves.

Our remote sensing methodology, if validated in other areas, might be useful for the evaluation of ecosystem health as well as for detection of prograding tropical areas characterized by sandy bottomsets. This method could thus be used to map and forecast the evolution of mangrove canopies in large tropical deltas where Landsat images are available. Finally, our study highlights the impact of sediment characteristics and availability on the health of Sonneratia forests in the Mekong River delta, with important consequences for restoration projects.

\section{Acknowledgements}

This research was supported by the by the ONR award N00014-14-1-0114 and by the ACSPRF program award51128-ND8. We would like to thank Võ Lương Hồng Phước, Nguyễn Hoàng Phong, Richard Nguyen, Daniel Culling, Aaron Fricke and Charles Nittrouer for the logistical support during field work. 


\section{References}

Aschbacher, J., Ofren, R. S., Delsol, J. P., Suselo, T. B., And Charrupat, T., An integrated comparative approach to mangrove vegetation mapping using remote sensing and GIS technologies: preliminary results. Hydrobiologia Biology, 1995, 295, 285-294.

Asrar et al.,G. Asrar, M. Fuchs, E.T. Kanemasu, J.H. Hatfield, Estimating absorbed photosynthetic radiation and leaf area index from spectral reflectance in wheatAgron. J., 76 (1984), pp. 300-306.

Balke, T., Webb, E. L., van den Elzen, E., Galli, D., Herman, P. M. J., Bouma, T. J. (2013), Seedling establishment in a dynamic sedimentary environment: a conceptual framework using mangroves. Journal of Applied Ecology, 50: 740-747. doi: 10.1111/1365-2664.12067.

Blasco, F., Aizpuru, M., Gers, C., "Depletion of the mangroves of continental Asia", Wetlands Ecol. Manage. 9, 245-256, 2001.

Blott, S.J., Pye, K., 2001. GRADISTAT: a grain size distribution and statistics package for the analysis of unconsolidated sediments. Earth Surf. Process. Landf. 26, 1237 - 1248.

Dilworth, J. R., \& Bell, J. F. (1975). Variable plot cruising. In J. R. Dilworth (Ed.), Log scaling and timber cruising Corvallis, OR: Oregon State University Book Store, Inc.

Duke, N.C., and Jackes, B.R., 1987. A systematic revision of the mangrove genus Sonneratia (Sonneratiaceae) in Australasia. Blumea 32:135-42.

Ellison, J. C. Impacts of sediment burial on mangroves. Mar. Pollut. Bull.1998, 37, 420426.

Fricke A.T., C. Nittrouer, A.S. Ogston, H.P. Vo-Luong, D. Culling (2016) Asymmetric progradation of a coastal mangrove forest, Cù Lao Dung, Vietnam: sediment dynamics to stratigraphy, AGU Ocean Sciences Meeting Abstract, 21-26 February, New Orleans, Louisiana MA. 
Gleason, S.M., Ewel, K.C. and Hue, N., 2003. Soil redox conditions and plant-soil relationships in a Micronesian mangrove forest. Estuarine, Coastal and Shelf Science, 56(5), pp.1065-1074.

Grosenbaugh, L. R. 1952 Plotless timber estimates — new, fast, easy. J. Forest. 50: 32- 37.

Kerr, J.T. and Ostrovsky, M. 2003: From space to species: ecological applications for remote sensing. TRENDS in Ecology and Evolution 18, 299-305.

Kuenzer, C., Bluemel, A., Gebhard, S., Quoc, T. V., Dech, S., "Remote Sensing of Mangrove Ecosystems: A Review”, Remote Sensing, 3, 878-928, 2011.

Léonard, J. and Richard, G., (2004). Estimation of runoff critical shear stress for soil erosion from soil shear strength. Catena, 57(3), pp.233-249.

Lin, G. H., \& Sternberg, L. D. S. (1992). Effect of growth form, salinity, nutrient and sulfide on photosynthesis, carbon isotope discrimination and growth of red mangrove (Rhizophora mangle L.). Functional Plant Biology, 19(5), 509-517.

Masek, J.G., E.F. Vermote, N. Saleous, R. Wolfe, F.G. Hall, F. Huemmrich, F. Gao, J. Kutler, and T.K. Lim, A Landsat surface reflectance data set for North America, 19902000, Geoscience and Remote Sensing Letters, 3, 68-72, 2006.

McKee, K. L. 1993. Soil Physicochemical Patterns and Mangrove Species Distribution-Reciprocal Effects? Journal of ecology, 477-487.

Mekong River Commission, official website: http://www.mrcmekong.org/ Nardin William, Silvia Locatelli, Valerie Pasquarella, Maria Cristina Rulli, Curtis E. Woodcock and Sergio Fagherazzi, Dynamics of a fringe mangrove forest detected by Landsat images in the Mekong delta, Vietnam. Earth Surface Processes and Landforms 2016 (in review). 
Nguyen, V.L., Ta, T.K.O., and Tateishi, M., 2000, Late Holocene depositional environments and coastal evolution of the Mekong River Delta, southern Vietnam: Journal of Asian Earth Sciences, v.18, p.427-439, doi: 10.1016/S1367- 9120(99)00076-0

Phan, N. H. and T.S. Hoang. 1993, Mangroves of Vietnam, IUCN Wetlands. ISBN X283170166: 9782831701660. Bangkok, Thailand.

Rogers, K., N. Saintilan and D. Cahoon (2005). Surface Elevation Dynamics in a Regenerating Mangrove Forest at Home bush Bay, Australia. Wetlands Ecology and Management 13(5): 587-598.

Sellers, P.J., Hall, F.G., Asrar, G., Strebel, D.E. and Murphy, R.E. (1992). An overview of the First International Satellite Land Surface Climatology Project (ISLSCP) Field Experiment (FIFE). Journal of Geophysical Research 97: doi: 10.1029/92JD02111. issn: 0148-0227.

Silvestri, S., Defina, A., and Marani, M. (2005). Tidal regime, salinity and salt marsh plant zonation. Estuarine, Coastal and Shelf Science, 62(1), 119-130.

Simard, M., V. H. Rivera-Monroy, J. E. Mancera-Pineda, E. Castaneda-Moya, and R. R. Twilley (2008), A systematic method for 3d mapping of mangrove forests based on shuttle radar topography mission elevation data, ICESat/GLAS waveforms and field data: Application to Cienaga Grande De Santa Marta, Colombia, Remote Sens. Environ. Sims, N.C., M.C. Thoms, 2002. What happens when floodplains wet themselves: vegetation response to inundation on the Lower Balonne Floodplain, International Association of Hydrological Sciences, 276 (2002), pp. 195-202.

Spalding, M., Kainuma M., and Collins L. (2010). World atlas of mangroves. Earth scan, London, 304 pp., ISBN-13: 978-1844076574 
Ta, T.K.O., Nguyen, V.L., Tateishi, M., Kobayashi, I., and Saito, Y., 2002, Holocene delta evolution and sediment discharge of the Mekong River, southern Vietnam: Quaternary Science Reviews, v. 21, p. 1807-1819, doi: 10.1016/S0277-3791(02)00007-0.

Ta, T.K.O., Nguyen, V.L., Tateishi, M., Kobayashi, I., and Saito, Y., 2005, Holocene delta evolution and depositional models of the Mekong River delta, southern Vietnam, in Giosan, L., and Bhattacharya, J.P., eds., River deltas - Concepts, models, and examples: Society for Sedimentary Geology Special Publication 83, p. 453-466.

Tamura, T., Horaguchi, K., Saito, Y., Nguyen, V.L., Tateishi, M., Ta, T.K.O., Nanayama, F., and Watanabe, K., 2010, Monsoon-influenced variations in morphology and sediment of a mesotidal beach on the Mekong River delta coast: Geomorphology, v. 116, p. 1123, doi:10.1016/j.geomorph.2009.10.003.

Tanabe, S., Ta, T.K.O., Nguyen, V.L., Tateishi, M., Kobayashi, I., and Saito, Y., 2003, Delta evolution model inferred from the Holocene Mekong delta, southern Vietnam, in Sidi, F.H., et al., Tropical deltas of Southeast Asia—Sedimentology, stratigraphy, and petroleum geology: Society for Sedimentary Geology Special Publication 76, p. 175188.

Thampanya, U., J. E. Vermaat, and J. Terrados (2002), The effect of increasing sediment accretion on the seedlings of three common Thai mangrove species, Aquatic Botany, 74(4), 315-325.

Thampanya U., Vermaat J.E., Sinsakul S., Panapitukkul N. (2006) Coastal erosion and mangrove progradation of Southern Thailand. Estuar. Coast. Shelf Sci. 68:75-85

Thu, P.M.; Populus, J. Status and changes of mangrove forest in Mekong Delta: Case study in Tra Vinh, Vietnam. Estuar. Coast. Shelf Sci. 2007, 71, 98-109. 
Tong, P.H., Auda, Y., Populus, J., Aizpura, M., Habshi, A.A., Blasco, F., “Assessment from space of mangroves evolution in the Mekong Delta; in relation to extensive shrimp farming”. Int. J. Remote Sens. 25, 4795-4812, 2004.

Wang, L.; Silván-Cárdenas, L.; Sousa, W.P. Neural network classification of mangrove species from multi-seasonal Ikonos imagery. Photogramm. Eng. Remote Sensing 2008, 74, 921-927. Watts, C.W., Tolhurst, T.J., Black, K.S. and Whitmore, A.P., (2003). In situ measurements of erosion shear stress and geotechnical shear strength of the intertidal sediments of the experimental managed realignment scheme at Tollesbury, Essex, UK. Estuarine, Coastal and Shelf Science, 58(3), pp.611-620.

Woodroffe, C.D., (2002). Coasts: form, process and evolution. Cambridge University Press., 640 pages, Cambridge, ISBN-13:978-0521011839.

Zhu, Z., \& Woodcock, C. E. (2012). Object-based cloud and cloud shadow detection in Landsat imagery. Remote Sensing of Environment, 118, 83-94. 